\title{
Migration, Intensification, and Diversification as Adaptive Strategies
}

\author{
Andrew Bell ${ }^{1}$, Carlos Calvo Hernandez ${ }^{1}$, and Michael Oppenheimer ${ }^{2}$ \\ ${ }^{1}$ New York University, New York, USA \\ ${ }^{2}$ Princeton University, New Jersey, USA
}

\begin{abstract}
Agent-based modeling ( $A B M)$ has transformed the century-old field of mechanistic migration modeling, by shifting the unit of analysis from the city (in the gravity model) to the individual decision maker. Various efforts over the past decade have leveraged ABM tools to integrate competing labor opportunities, climatic shocks, and sharing across networks into decision-based models of migration patterns. We present the MIDAS (Migration, Intensification, and Diversification as Adaptive Strategies) framework, which draws on the 'push-pull-mooring' (PPM) theory of migration to integrate the influences of social networks, climatic shifts, and opportunities for livelihoods diversification on migration in a single framework. We demonstrate some of the strategic responses to opportunities that are possible in a true PPM modeling framework, including substitution of income streams, the choice to specialize or diversify, as well as to migrate in response to shocks. We observe what may be the emergence of a distinct class of agents within one of our experiments, highlighting the value of tools like MIDAS to capture migration and adaptive behaviors under conditions for which analogs do not yet exist in census datasets or otherwise. Importantly, we show how adaptation decisions depend strongly on a small number of behavioral parameters, key among them preferences for risk, for different forms of utility, and for time.
\end{abstract}

Keywords

Agent based modelling; migration; intensification

\section{Introduction}

Research in sustainable livelihoods commonly considers livelihoods as a portfolio of activities that can be specialized or intensified in particular activities, diversified across different activities, or include migration (shortor long-term) to other locations (Barrett et al., 2001; Bollig, 2016; Cannon, 2013; Hussein \& Nelson, 1998; Kuipers, 2014). Demographic theory to interpret migration alongside these activities in a livelihoods context began by thinking of 'push' and 'pull' factors that motivated people to stay in one place or move elsewhere, with 'intervening' factors constraining how and if any moves occurred (e.g., Bogue 1969); later theory amended the notion of intervening factors within a more formal concept of 'moorings' (e.g., Moon 1995) in what is now the 'push-pull-mooring' or PPM theory of migration. Moorings may be broadly understood as specific aspects of an individual's 'place utility' (Adams \& Adger, 2013) that tie them to a place, including family or assets, love of place; or other factors contributing to inertia or status quo bias (Sun et al., 2017).

Correspondence:

Contact A. Bell at andrew.reid.bell@nyu.edu

Cite this article as:

Bell, A., Calvo Hernandez, C. \& Oppenheimer, M.

Migration, Intensification, and Diversification as Adaptive Strategies

Socio-Environmental Systems Modelling, vol. 1, 16102, 2019, doi:10.18174/sesmo.2019a16102

This work is licensed under a Creative Commons Attribution-NonCommercial 4.0

International License.

\section{Socio-Environmental Systems Modelling}

An Open-Access Scholarly Journal

http://www.sesmo.org 
Research over the last decade has placed migration (including commuting and temporary or seasonal migration) as a legitimate component of a livelihoods strategy, as opposed to something to avoid and prevent (Scheffran et al., 2012; Tacoli, 2009), with the caveat that voluntary moves to improved livelihoods are preferred to involuntary forced moves (Adger et al., 2009; Barnett \& Webber, 2010). Along a similar timeline, advances in computing power have allowed transformational changes in the way migration is modeled on computers, from looking only at places to looking directly at people. We present a novel framework for migration modeling that allows migration decisions to emerge alongside other livelihood strategies such as intensification and diversification.

\subsection{Modeling migration}

The literature on modeling migration is quite rich and long, beginning with the 'gravity model' in the 19th century (Ravenstein, 1885), and dominated by variations on this model over much of the intervening century (Anderson, 2010). The gravity model draws an analogy to Newton's law of universal gravitation, positing that movement between any two places will increase with the importance and closeness of those places (much as the attraction between two bodies varies with mass and distance). It is readily adapted to econometric frameworks allowing researchers to take advantage of the increasing availability of large data sets (e.g., Mastrorillo et al., 2016). These models can be extended to accommodate labor market effects as drivers (Borjas, 1987; Roy, 1951). However, a historical challenge in linking model with theory in the migration context then has been that such models have a location as a basic unit of analysis, while the basis of a migration decision is fundamentally an individual. In recent years, the advent of agent-based modeling (ABM) as an approach - in which interacting, decision-making agents are the units of analysis, from whose communities emerge system-level outcomes (Hare \& Deadman, 2004) - has made modeling of migration from the perspective of an individual migrant possible. This makes possible the modeling of migration as part of a livelihood strategy, as per the thinking of Ober (2014) or Adger et al. (2015), and the analysis of linkages from governance measures through to targeted and affected groups within a numerical simulation.

Klabunde and Willekens (2016) review the current landscape of ABM and the related approach of microsimulations (which model individuals but typically represent decision outcomes probabilistically, based in many cases on econometric data, rather than through careful structural representation; e.g., Kennan and Walker 2011) that tackle the challenge of migration. They note that examples of migration modeling in ABM are still few, and are mostly uncoordinated, without yet building upon one another. Some models carefully develop models of competing labor opportunities (e.g., Espindola et al. 2006); others allow climate effects to shape the migration decision (e.g., Naivinit et al. 2010; Kniveton et al. 2012); still others incorporate sharing across social networks as a mediating factor in the willingness or ability to migrate (e.g., Filho 2011). Importantly, following on Klabunde and Willekens' insight that the field is not yet building itself out, there is not yet a published model that captures all of the critical elements of sustainable livelihoods to properly examine migration decisionmaking as one of several strategies to adapt to shifting opportunities, such as under climate change. Through our review, we have identified two modeling efforts that illustrate research frontiers in this regard.

Kniveton et al. (2012) develop an ABM of rainfall effects on migration in Burkina Faso, with Smith (2014) applying the same structure to individual migration decisions within a larger household model of adaptation and decisionmaking. These applications apply the Theory of Planned Behavior (Ajzen, 1991), which focuses on how perceived social norms and other constraints on behavior moderate a behavioral intention (in this case, to migrate). Both applications derive the likelihood of an agent of a particular demographic (by age, gender, etc.) migrating under particular rainfall conditions from secondary historical data, and adjust this probability by perceived social factors (peers who have also migrated) and, in Kniveton et al. (2012), perceived controls (assets and experience). This approach is noteworthy for making use of secondary data on migration, but does so in a way (a statistical model of migration likelihood) that largely sidesteps the challenge of modeling the intention to migrate. Rather, the major focus of the Kniveton et al. (2012) model is on the following step, where intention translates to actual migration decisions (which is the domain of the Theory of Planned Behavior), but as the authors lack data on social networks, they are forced to model them in an arbitrarily simple way (uniform set of 20 social network connections for all agents).

A second approach by Hassani-Mahmooei and Parris (2012) offers a prototype for how PPM theory might be implemented in an ABM to model the decision to migrate. Their work models internal migration in Bangladesh, 
with each of Bangladesh's 64 districts modeled as a node at which individual agents may derive a livelihood. They do not explicitly describe all aspects of the model (livelihood opportunities and social networks are missing) but the contribution and limitations of the work are clear. As in Kniveton et al. (2012), Hassani-Mahmooei and Parris (2012) use secondary data where available to calibrate the initial density of agents in each district, their access to amenities and ownership of assets. However, lacking data on how different factors ought to weigh against each other in the livelihoods decision process, they develop arbitrary random functions to describe intervening and pull factors; climate variables are similarly randomly derived. Most importantly, they implement PPM as a two-step process: only if push factors exceed some arbitrary threshold, then agents will consider pull factors to identify a suitable new home. Critically, this behavior decouples push from pull in jointly shaping a migration decision, in a way that is not consistent with PPM theory.

Key limitations in both models are that i) migration is the designed-in object of the decision algorithm (as opposed to an emergent strategy among others), and ii) migration is considered explicitly (and nearly exclusively) as a response to a climatic variable (rainfall). This structure precludes both the emergence of migration i) as a particular strategy alongside other livelihood strategies such as economic specialization/intensification, or income diversification, and ii) as a response to multiple factors not necessarily correlated to climate (e.g., emerging industrial opportunities). Particularly given the paucity of migration data attributed clearly to climate (Mueller et al., 2014), the capacity to examine climate effects within the larger context of other migration motivations (for which a larger history may be available) is important. An additional missed opportunity is the exploration of the multiple services provided across social networks (jobs information, social capital, insurance, etc.; e.g., Munshi 2003; Munshi and Rosenzweig 2016) that have been focal in other models (e.g., Filho 2011) as well as their role in shaping all pushes, pulls, and moorings.

In this study we present a modeling framework designed to overcome these limitations at the frontier of migration ABM. The Migration, Intensification, and Diversification as Adaptive Strategies (MIDAS) modeling framework allows migration to emerge alongside other livelihood strategies, in a decision structure that embeds income streams, use values, place utility, and social network sharing. In this manner, it is consistent with PPM theory in a way that previous PPM models have not been. We apply MIDAS in the present study to a stylized set of data representing income and housing in the United States and Mexico, in order to demonstrate the range of livelihood strategies that MIDAS can represent, and to highlight the forms of data that are most important to developing well-validated MIDAS applications.

\section{Methods}

A complete description of the MIDAS framework following the ODD+D Protocol (Müller et al., 2013) is provided as Supplementary Material A. In this section we provide an overview of the framework, our data sources, and introduce our experimental design.

\subsection{The MIDAS Framework}

MIDAS represents locations as nodes with place-specific opportunities for agents to derive utility - from regular sources of income, as well as from assets and local social and cultural amenities (Figure 1). Some opportunities are common to many places (e.g., teaching jobs, food marketing, etc.) while others are less so (e.g., ranching work; access to mountains or lakes, good health care and schools, or affordable homes, etc.). Accessing opportunities may carry costs (e.g., obtaining a teaching license), which may give the agent access to the same opportunity in many places (e.g., passing the bar exam to practice law across an entire state), or only one (e.g., purchasing a home in a specific place). Agents occupy nodes, access a portfolio of different utility sources (described by the cost of access, time commitment, and per-time period utility), and are embedded in a social network (Figure 1). Agents share both income and information across their social network, with the likelihood and cost of sharing varying both with the strength of the link (i.e., closeness of the relationship) and the distance across which the relationship is stretched. 


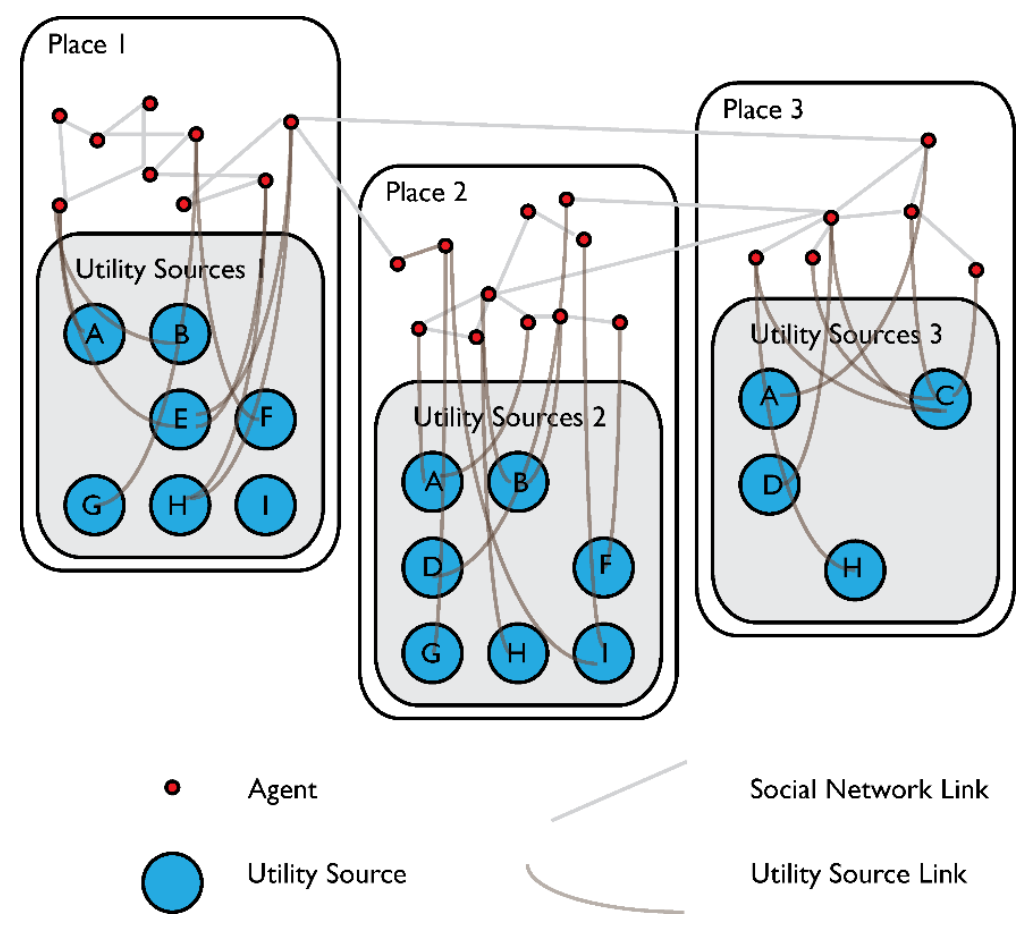

Figure 1: MIDAS model structure of agents occupying place-specific sources of utility. Agents (red circles) exist in places, are embedded in social networks (grey straight lines), and draw utility from specific utility sources (brown curved lines).

In each time step, with agent-specific likelihoods, agents participate in social interactions across their networks, and (again, with agent-specific likelihoods) re-evaluate the appropriate portfolio of utility sources for them to pursue. In this decision process, agents compare possible portfolios both within their current location, as well as in alternate locations about whose opportunities they may have learned through their social networks or otherwise. As currently implemented, comparisons are made with a boundedly-rational (small number - e.g., 2 to 5 - of possible portfolios, including past options as well as randomly selected options), future-discounting prospect theory framework, in which losses are disliked approximately twice as much as gains (Kahneman, 2003). Agents select the portfolio that would maximize utility over some future time horizon $t$, with the utility that agent $k$ would derive for a particular portfolio of opportunities $i$ in a particular place $m$ calculated by:

$$
U_{k, i, m}=\left\{\begin{array}{cc}
\sum_{t}\left[\frac{\left(\beta_{1, k} B+\beta_{2, k} D\right)^{1-r_{k}}}{1-r_{k}}\right]^{-\left(1+d_{k}\right)^{t}} & ; \beta_{1, k} B+\beta_{2, k} D \geq 0 \\
P \cdot \sum_{t}\left[\frac{\left[\operatorname{abs}\left(\beta_{1} B+\beta_{2} D\right)\right]^{1-r_{k}}}{1-r_{k}}\right]^{-\left(1+d_{k}\right)^{t}} & ; \beta_{1, k} B+\beta_{2, k} D<0
\end{array}\right\}
$$

where $r$ is a coefficient capturing agent $k^{\prime}$ s constant relative risk aversion, and $d$ is agent $k^{\prime}$ s discount rate. $B$ represents net income and $D$ represents a non-monetary use value, while the coefficients $B_{1, k}$ and $B_{2, k}$ represent preference coefficients placed by agent $k$ on $B$ and $D ; B$ is given as

$$
B=\left[\sum_{i}\left(R_{i, m, t}-C_{i, m, t}\right)+\sum_{j}\left(I_{j, t}-O_{j, t}\right)\right]
$$

where $R$ represents the value derived by agent $k$ from the opportunity $i$ and $C$ is the cost to access it, $I$ represents resources received from a particular network connection $j$ and $O$ represents resources shared to a particular connection $j$. The condition $\left[B_{1, k} B+B_{2, k} D<0\right]$ represents a net loss - where costs exceed income plus any other use value or benefit - and the parameter $P$ scales the disutility of losses as per prospect theory, set to -2 in our simulations following Kahneman's work. Net values are summed across all opportunities in the portfolio, as are the net shared resources across the social network, for agent $k$ as well as (optionally) additional members of their social network. This last term allows the possibility that agents may be optimizing welfare of their extended 
network, rather than only themselves. The incorporation of risk preferences allows the possibility of preferences for smoother income streams, and thus the emergence of strategies (such as diversification) to reduce variability in utility from period to period. We also highlight that, consistent with recent pushes to improve re-usability and sharing in ABM (Bell et al., 2015), this particular decision-model can be easily substituted for another structure, or possibly included as one of several possible decision structures within the same framework. All code, along with the ODD+D protocol describing MIDAS, is downloadable from https://github.com/andrewnyu/migration (Bell, 2016).

The representation of livelihoods as a portfolio of sources, coupled with sharing across a network, provides a unified framework to capture particular household strategies as well as adaptive outcomes as treated elsewhere in the adaptation and migration literature (Table 1), so that migration in its different forms is able to emerge alongside other strategies (such as diversification) without assuming hierarchy in decision-making. Moreover, this allows for an implementation of the PPM model more consistently than in previous models, as all of the push factors (e.g., downturn in access to utility in current location from formal sources or through social network), pull factors (e.g., knowledge of improved opportunities elsewhere, or movement of close social ties to a new location), and moorings (e.g., close local social ties, assets, or 'sense of place' represented as sources of utility) are considered simultaneously.

Table 1: Example adaptive strategies and outcomes in the MIDAS Framework

\begin{tabular}{|c|c|}
\hline Agent condition & Identifier in MIDAS framework \\
\hline Trapped Household & $\begin{array}{l}\text { Loss of access to sufficient portfolio in home location, without knowledge or resources to } \\
\text { migrate }\end{array}$ \\
\hline Involuntary Migrant & Loss of access to sufficient portfolio in home location, leading to migration \\
\hline Voluntary, Seasonal Migrant & Improvement of portfolio in home location via short-term migration to new location \\
\hline Permanent Migrant & Long-term adoption of portfolio in new location, including local-only utility sources (moorings) \\
\hline Diaspora-enabled Migrant & Migration decision driven strongly by access to sharing across social network at new location \\
\hline $\begin{array}{l}\text { Intensification/Specialization } \\
\text { Household }\end{array}$ & $\begin{array}{l}\text { Investment in access to smaller number of higher-return utility sources in portfolio in home } \\
\text { location }\end{array}$ \\
\hline Diversification Household & Spreading across larger number of less-correlated utility sources in portfolio in home location \\
\hline
\end{tabular}

\subsection{Data}

MIDAS requires specification of i) sources of utility, ii) costs to access these utility layers, iii) costs for moving, and iv) costs for sending remittances. In this application of MIDAS, utility sources include income sources and home ownership. The income data for this model was adapted from national-level surveys for ten economic activities in Mexico and the United States:

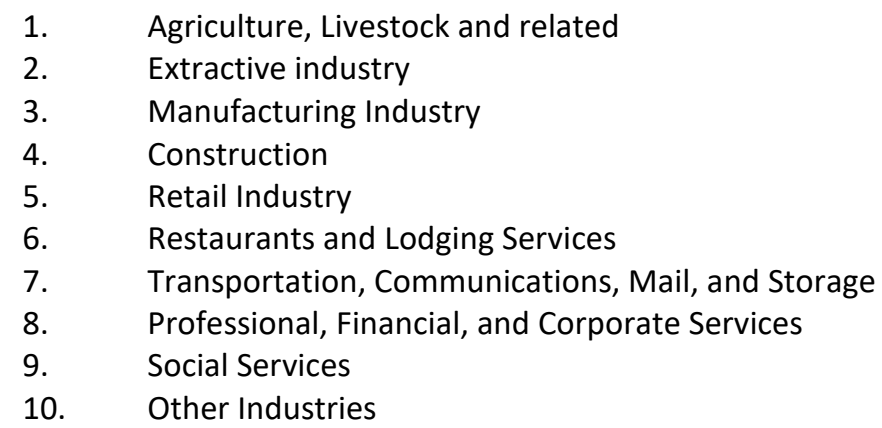

For Mexico, the data used was the National Survey of Occupation and Employment (Encuesta Nacional de Ocupación y Empleo) from Mexico's National Institute of Statistics and Geography (Instituto Nacional de Estadística y Geografía - INEGI) (INEGI, 2017). This quarterly data is available from 2005 to 2017. For this paper, we selected the period 2005-2013. The ENOE data is at the individual level. We excluded observations allocated outside of the workforce, those not coded as employee or wage laborer, and if they were not receiving wages during the period. The income variable was calculated from the product of the minimum wage earned times the 
income level provided. This resulted in the income amount in Mexican Pesos for surveyed individuals. We calculated the total population represented from every state in order to compute the average income by state and by economic activity.

Data for the United States was retrieved from the Bureau of Labor Statistics' Quarterly Census of Employment and Wages (QCEW) for the same 2005-2013 year range (US Bureau of Labor Statistics, 2017). We selected the income in that period by state, private employers, and economic activity. The base data is structured in weekly time steps, which we aggregated to create quarterly data. To standardize U.S. data in dollars to Mexican Pesos, purchasing power parity (PPP) data was used from the OECD Data website (https://data.oecd.org) for each corresponding year and used to convert currencies.

Base moving costs across political borders in the model are assumed in this model by constant values $(5,000$ same country, different state, and 8,000 different country), all in Pesos. Distance costs were created by assigning a Beta probability density function to the interval of minimum and maximum distances present in the map used, while keeping the minimum $(10)$ and maximum $(10,000)$ costs fixed. These assumptions gave a rule that made longer moves more costly, but shorter moves easier and cheaper to accomplish.

Access costs data for access to the U.S. was collected from the U.S. Embassy \& Consulates in Mexico (2018) website and converted to Mexican Pesos using the PPP data used for the income data. Access costs were informed by visa costs (in the case that agents moved to the U.S.) and by "training" costs in the case of accessing other income opportunities, even in the same locations where they are. These training costs are arbitrary in nature, but hope to portray a sense of differentiation in what "skills" agents need to develop in order to access those income opportunities. We assume basic agriculture is the most readily available opportunity everywhere, and as such, requires no "training" of this kind.

Remittance costs were created from data from the World Bank's “Remittance Price Worldwide: Making Markets More Transparent" database (World Bank, 2017). The available data only covers partially the years 2008 to 2017 , so we created an average fee and exchange rate margin from the available data in this database.

Housing data for every state was collected from different sources for both countries. For Mexico, the average market value per state was chosen from the Housing Statistics Database of the Federal Mortgage Association (Sociedad Hipotecaria Federal, 2018). For the U.S. an average of median home prices was constructed from Zillow (2018) and Trulia (2018). Prices were converted with the same OECD Data PPP rates. We calculated the cost of accessing the housing layer (i.e., buying a house) as the average market value for a house, and estimated the per-quarter 'use value' as the average market value divided by a factor of 20; this is a loose, stylized assumption meant only to elevate the use value of a home into an important part of the migration decision for agents. The value of 20 has no special meaning, other than implying that (with 4 time steps per year) it would take 5 years to recoup the cost of the home through use value, and creating conditions whereby the purchase of a home is favorable to some but not all agents. A more careful assessment of the factors shaping use value of a home could include comparison of local rental rates, assessment of reduced risks through ownership, etc.

\subsection{Experimental Design}

We designed an evaluation of MIDAS with the goals of producing a range of behaviors and strategies, and identifying the most important parameters for model calibration and validation. This exercise is itself not intended as a calibration nor validation exercise, and the stylized representations of utility sources presented below should not be considered careful reflections of on-the-ground reality in the US and Mexico.

For each state in Mexico and the contiguous United States ( 81 'places'), we drew average, quarterly income rates for each of 10 different income sources contained in our data sources, and from these constructed stylized timelines that repeated these annual cycles over 50 years (50 years $x 4$ periods per year $=200$ time steps). Additionally, each place has a single 'mooring' layer modeled after home ownership. With an access cost equal to local average house prices for that place, agents may access a layer that provides 'use value' nominally equal to $1 / 20$ th of the access price in each time step; agents have a utility coefficient on use value that is independent of their utility on income. We designate this set of stylized income layers as our 'baseline.' 
We then designed three deviations from this baseline, outlined in Figure 2. In the 'Specialization' variation, additional income layers are available that are similar to the original 10, varying by i) having additional cost of entry, ii) requiring additional time commitment, and iii) offering higher wage rates - simulating specialization and investment into particular professions. In the 'Agricultural Shock' variation, there is a shock to agricultural income in Year 10 of $50 \%$ of the available income during 4 years and a recovery period of 2 years with $75 \%$ of the original income available; in the 'Full Shock' variation, there is an analogous shock to all layers in Mexico for 5 years in Year 10 with a 2 year recovery period, simulating a complete economic collapse.
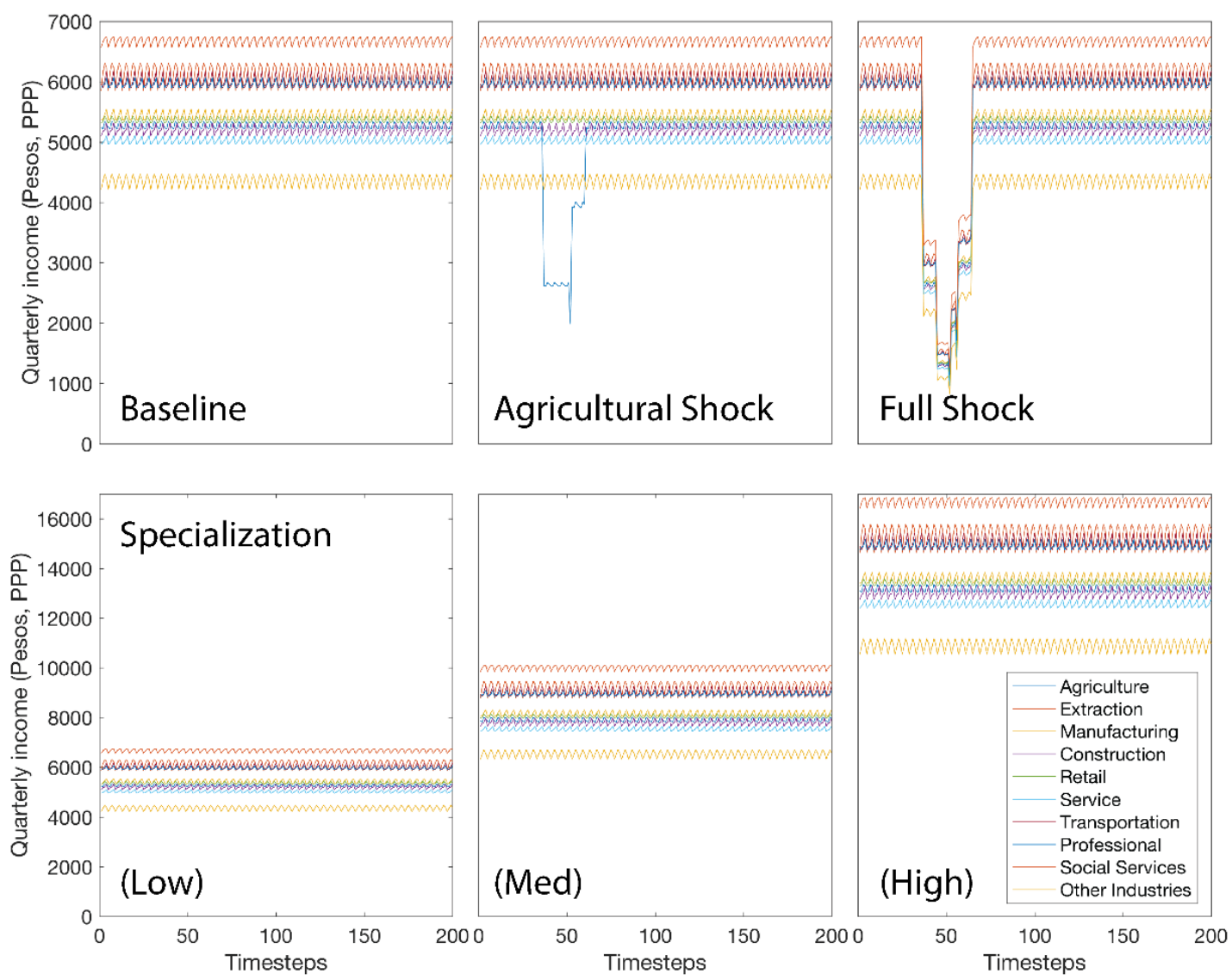

Figure 2: Illustration of income source layers in Baseline (top left), Agricultural Shock (top middle), Full Shock (top right), and Specialization variants (bottom). Oscillations reflect variation along year revealed in quarterly data (Section 2.2).

With these four experimental conditions (Baseline, Agricultural Shock, Full Shock, and Specialization) designed, we conducted a large- $n$ Monte Carlo simulation with model parameters drawn randomly from the ranges outlined in Table 2. In each simulation, the experimental condition for each place was drawn randomly, so that each simulation run contains places set up with a mix of experimental conditions. We present results here from a set of 260 simulation runs (Sample run shown in Figure 3), with results for 21060 places, and 776737 agents.

\subsection{Analytical methods}

To identify key parameters shaping our outcomes of interest across these simulations, we applied the randomForest algorithm, as implemented in Matlab's TreeBagger routine, training a 'forest' of 100 different regression 'trees' on available data to predict key outcomes of migration and wealth. For specific parameters and relationships of interest, we tested differences using the Wilcoxon rank-sum test for paired differences across places (when examining differences at the place level in our experimental variant analyses) and the Kolmogorov-Smirnoff test for differences across heterogeneous populations of agents. All tests were conducted at $5 \%$ significance. 
Table 2: Parameter descriptions and ranges for Monte Carlo analysis

\begin{tabular}{|c|c|c|c|}
\hline Parameter name & Min. & Max. & Description \\
\hline numAgents & 1000 & 5000 & Number of agents in simulation \\
\hline networkDistanceSD & 5 & 15 & $\begin{array}{l}\text { Factor shaping structure of agent network; lower values mean more } \\
\text { connections in agent's home place, while higher values mean more } \\
\text { connections in other places }\end{array}$ \\
\hline connectionsMean & 1 & 5 & \multirow{2}{*}{$\begin{array}{l}\text { Mean and standard deviation of number of connections in agent } \\
\text { network }\end{array}$} \\
\hline connectionsSD & 1 & 3 & \\
\hline incomeShareFractionMean & 0.2 & 0.6 & \multirow{2}{*}{$\begin{array}{l}\text { Mean and standard deviation of fraction of income to the agent shared } \\
\text { across social network in a given timestep }\end{array}$} \\
\hline incomeShareFractionSD & 0 & 0.2 & \\
\hline shareCostThresholdMean & 0.2 & 0.4 & \multirow{2}{*}{$\begin{array}{l}\text { Mean and standard deviation of fraction of the overall amount of a } \\
\text { remittance lost to transaction costs, above which the agent will choose } \\
\text { not to make that share }\end{array}$} \\
\hline shareCostThresholdSD & 0 & 0.2 & \\
\hline interactMean & 0.2 & 0.6 & \multirow{2}{*}{$\begin{array}{l}\text { Mean and standard deviation of likelihood of current agent to interact } \\
\text { with other agents to exchange information in a given timestep }\end{array}$} \\
\hline interactSD & 0 & 0.2 & \\
\hline randomLearnMean & 0 & 1 & \multirow{2}{*}{$\begin{array}{l}\text { Mean and standard deviation of likelihood of current agent to learn } \\
\text { new information about income opportunities randomly in a given } \\
\text { timestep }\end{array}$} \\
\hline randomLearnSD & 0 & 0.2 & \\
\hline randomLearnCountMean & 1 & 3 & \multirow{2}{*}{$\begin{array}{l}\text { Mean and standard deviation of number of new pieces of information } \\
\text { learned randomly, if agent learns randomly during a timestep }\end{array}$} \\
\hline randomLearnCountSD & 0 & 2 & \\
\hline chooseMean & 0.2 & 0.6 & \multirow{2}{*}{$\begin{array}{l}\text { Mean and standard deviation of likelihood of current agent to make a } \\
\text { decision about income portfolio in a given timestep }\end{array}$} \\
\hline chooseSD & 0 & 0.2 & \\
\hline knowledgeShareFracMean & 0.05 & 0.2 & \multirow{2}{*}{$\begin{array}{l}\text { Mean and standard deviation of fraction of their accumulated } \\
\text { knowledge (of opportunities in other places) shared with agents } \\
\text { during social interaction }\end{array}$} \\
\hline knowledgeShareFracSD & 0 & 0.05 & \\
\hline bestLocationMean & 1 & 3 & \multirow{2}{*}{$\begin{array}{l}\text { Mean and standard deviation of number of good node/locations agent } \\
\text { will retain in memory from previous decision making }\end{array}$} \\
\hline bestLocationSD & 0 & 1 & \\
\hline bestPortfolioMean & 1 & 3 & \multirow{2}{*}{$\begin{array}{l}\text { Mean and standard deviation of number of good portfolios from a } \\
\text { given location agent will retain in memory from previous decision } \\
\text { making }\end{array}$} \\
\hline bestPortfolioSD & 0 & 1 & \\
\hline randomLocationMean & 1 & 3 & \multirow{2}{*}{$\begin{array}{l}\text { Mean and standard deviation of number of node/locations agent will } \\
\text { draw randomly in decision making }\end{array}$} \\
\hline randomLocationSD & 0 & 1 & \\
\hline randomPortfolioMean & 1 & 3 & \multirow{2}{*}{$\begin{array}{l}\text { Mean and standard deviation of number of portfolios in a given } \\
\text { location agent will draw randomly in decision making }\end{array}$} \\
\hline randomPortfolioSD & 0 & 1 & \\
\hline numPeriodsEvaluateMean & 12 & 24 & \multirow{2}{*}{$\begin{array}{l}\text { Mean and standard deviation of number of time periods over which } \\
\text { agent will evaluate and compare different portfolios when making a } \\
\text { decision (parameter } t \text { in utility formula) }\end{array}$} \\
\hline numPeriodsEvaluateSD & 0 & 6 & \\
\hline numPeriodsMemoryMean & 12 & 24 & \multirow{2}{*}{$\begin{array}{l}\text { Mean and standard deviation of number of time periods of past } \\
\text { experience agent will hold in memory to inform decisions }\end{array}$} \\
\hline numPeriodsMemorySD & 0 & 6 & \\
\hline discountRateMean & 0.02 & 0.01 & \multirow{2}{*}{$\begin{array}{l}\text { Mean and standard deviation of agent's individual discount rate on } \\
\text { future time periods (parameter } d \text { in utility formula) }\end{array}$} \\
\hline discountRateSD & 0 & 0.0 & \\
\hline rValueMean & 0.5 & 1 & \multirow{2}{*}{$\begin{array}{l}\text { Mean and standard deviation of agent's individual constant relative } \\
\text { risk aversion coefficient (parameter } r \text { in utility formula) }\end{array}$} \\
\hline rValueSD & 0 & 0.2 & \\
\hline bListMean & 0.5 & 1 & \multirow{2}{*}{$\begin{array}{l}\text { Mean and standard deviation of utility coefficients describing relative } \\
\text { value placed by agent on i) income, ii) use value, or any other form of } \\
\text { utility source (parameters } B \text { in utility formula) }\end{array}$} \\
\hline bListSD & 0 & 0.4 & \\
\hline
\end{tabular}

\section{Results}

Though our experiment does not include a calibration exercise, we compare modeled net migration from our MIDAS runs with actual net migration data from INEGI 2005-2010 estimates (Figure 4), for illustrative purposes. In general we observe simulated migration rates to vary widely, which is perhaps unsurprising given that the 
modeled results span a broad set of Monte Carlo simulation parameters. It is perhaps noteworthy that the largest state by population (México, which includes the outer perimeter of Greater México City) experienced the greatest net in-migration over 2005-2010, and that MIDAS simulations also consistently predict net inmigration. However, MIDAS did not consistently predict the out-migration for central México City observed by INEGI over the period (possibly in expansion out to México State). Additionally, while for many states MIDAS predicted a range of in- and out-migration outcomes depending on parameterization, it consistently predicted steep out-migration for Morelos and Baja California - two states where slight in-migration was observed by INEGI, suggesting pull factors other than the income factors we included in our simulations.
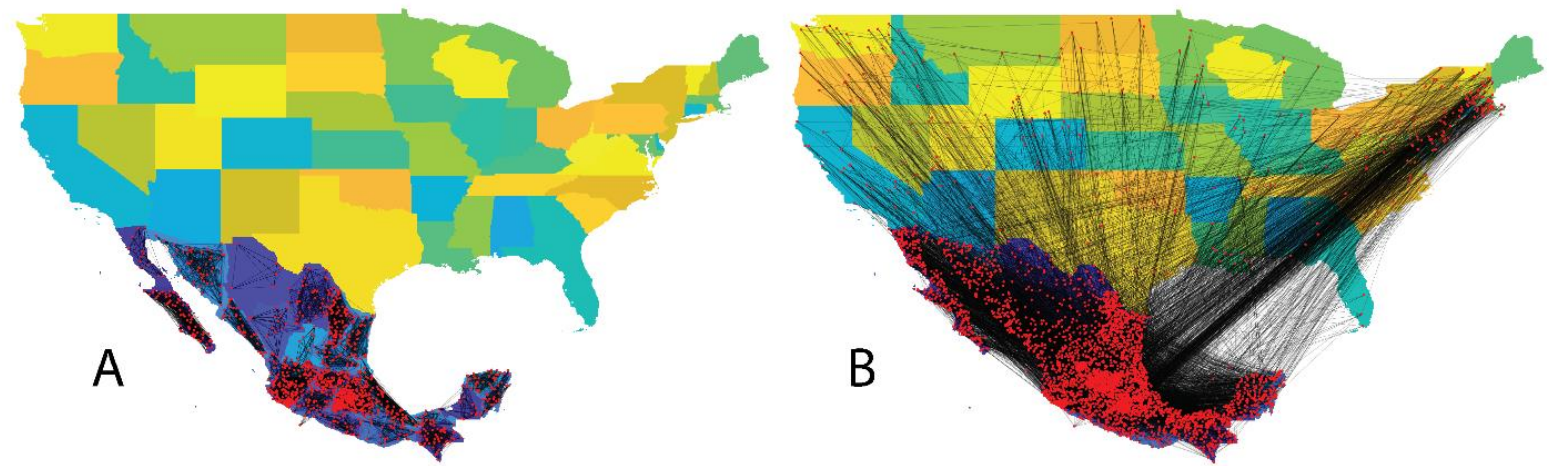

Figure 3: Sample MIDAS Run, showing agents in red, and social network connections as gray lines. Area shading shows administrative areas. A) Initial conditions with agents connected socially within their home place. B) Agents migrating within Mexico and the US, stretching social network connections across states and countries.

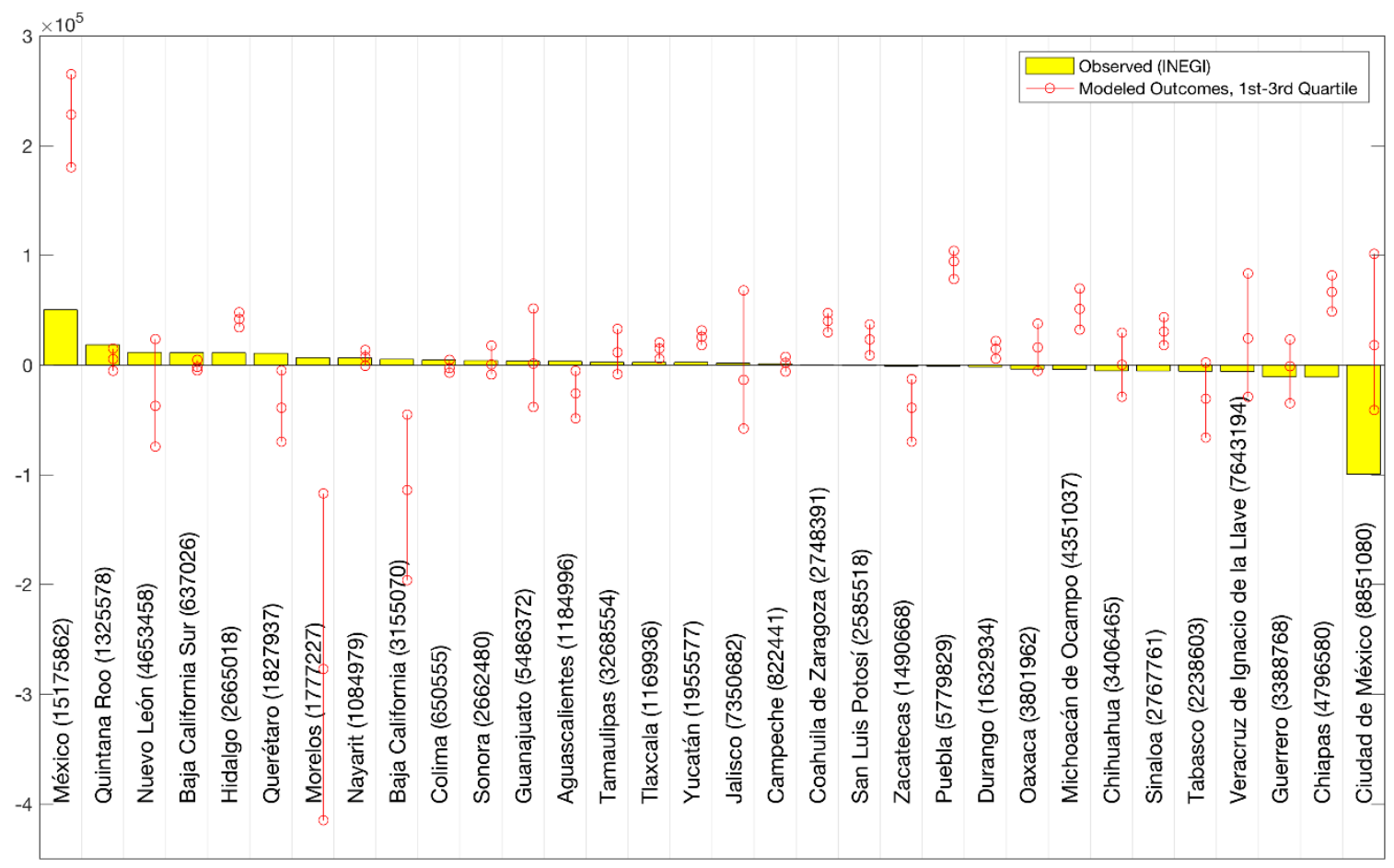

Figure 4: Comparison of modeled net migration with INEGI data. Yellow bars show net migration (in annual in-migrations per capita) from INEGI data, averaged over 2005-10. Red circles show interquartile range (1st to 3rd) of modeled net migration from MIDAS, rescaled to INEGI 2010 population.

A possible interpretation of these results is that the in-migration of México State is well predicted by income opportunities (the basis of our stylized dataset, and the premise underlying the history of gravity models of migration) while for most other states there are other important factors not captured by our simple set of utility layers, or not held in common across the different parameterizations of our Monte Carlo design. This helps to support our premise that other factors beyond income are important to understanding migration, and we 
devote our remaining efforts in this paper to identifying which other factors appear to be important in shaping migration behavior.

We are primarily concerned with a small number of outcomes - the accumulation of wealth by agents, the sources of utility they occupy, and how likely they are to migrate. We are able to examine the relative importance of model parameters in shaping these outcomes at several different scales - at the level of a simulation, at a particular place, and down to an individual agent.

\subsection{Random forest estimations of relative variable importance}

We examined the importance of different variables in predicting outcomes at three scales - the agent, the place, and the simulation. A complete list of all model parameters examined in this random forest exercise, along with all plots of relative variable importance, is included as Supplementary Material B accompanying this report. Here we present one example of this analysis (Figure 5), and highlight only those parameters identified as important in predicting outcomes across the different scales. Relative importance is measured as the increase in average prediction error across the 'forest' when the variable is withheld from inclusion in the 'trees,' compared across variables.

Examining the relative importance of model parameters at the simulation level, both the average wealth of agents in a simulation and the average number of moves by an agent are shaped most strongly by a small set of behavioral values - the mean and standard deviation of the distribution of risk coefficients, the mean of the distribution of discount rates, and the mean likelihood that an agent will choose to consider new portfolios in a given timestep. This is confirmed as well at the agent scale, with the specific risk coefficient and probability of choosing a new portfolio appearing as important variables, along with the size of an agent's network, and whether or not they own a home (the only 'mooring' layer in this set of experiments) (Figure 5).

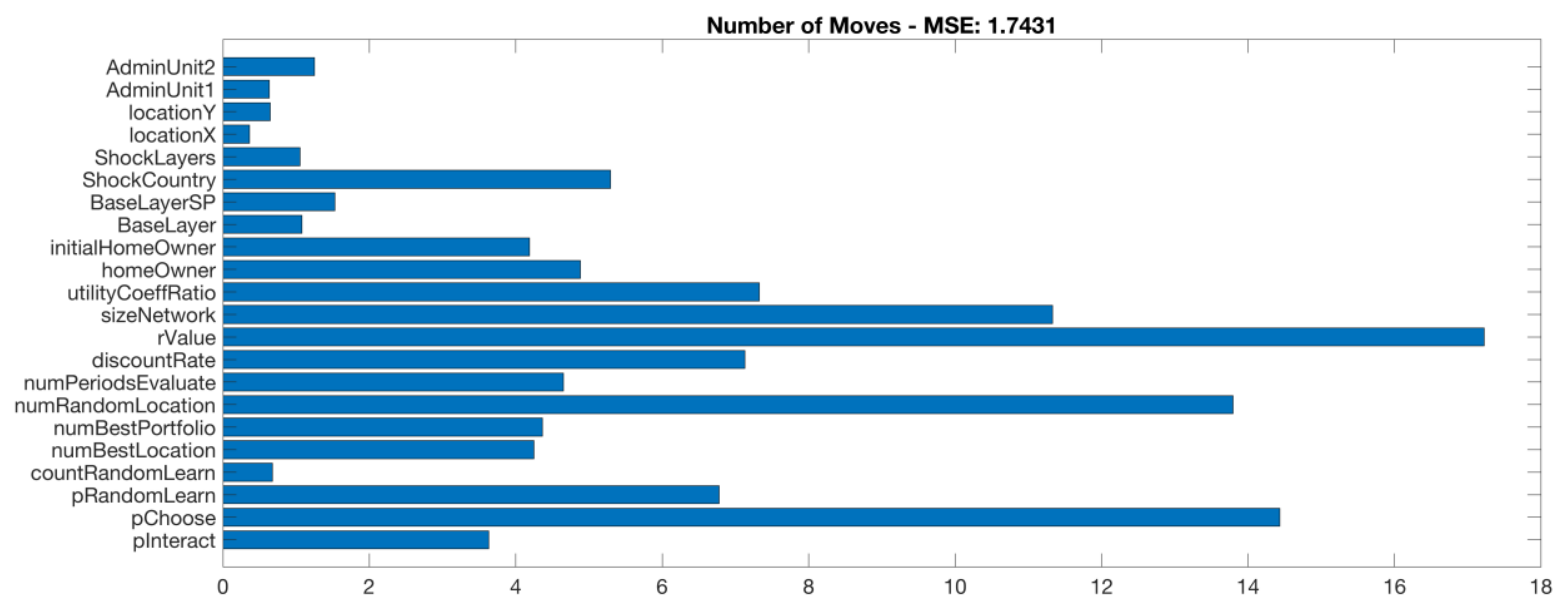

Figure 5: Relative variable importance measured by randomForest algorithm in predicting number of migrations per agent at agent scale. Additional analyses at simulation, place and agent scale included in Supplementary Material B.

At the place scale, we examine not characteristics of agents, but the effect of agent migrations as they manifest as net population growth. Here again, the mean of the distribution of risk coefficients and discount rate has a strong effect on net growth. More strongly however, we observe effects of location and experimental condition; we examine experimental effects in the following section.

The central finding of the random forest exercise, across all three scales, is that behavioral parameters - with the distribution of risk coefficients most consistent across analyses - are the most critical in influencing outcomes of agent wealth and migration. Additional important factors included home ownership and the conditions of our experimental variants, which we examine in the following sections. 


\subsection{Home ownership}

Across all variants, we included an additional 'mooring' layer of home ownership. This layer differs from the 10 basic income source layers in that agents are only able to access it (i.e., draw use value) in the place in which they paid for it; by contrast, the costs of accessing the 'extraction' layer, for example, entitle the agent the 'licence' (or training, certification, etc.) to access the same layer in many other places. It is this access feature that defines the home ownership as a mooring layer, and we observe this mooring function in our experiments. As part of the initial random assignment of portfolios, some agents were randomly assigned home ownership, with these agents moving significantly less than those who were not assigned home ownership, by KolmogorovSmirnov test at $5 \%$.

Agents are also able to purchase access to homes in other layers that they occupy as part of their livelihood portfolio, which emerges as relevant when we consider the Specialization variant in Section 3.3.2.

\subsection{Experimental condition effects}

We examined differences in outcomes among our experimental conditions via our Monte Carlo design, randomizing in each simulation run whether a particular place is set up as the baseline condition or one of the experimental variants. Differences between experimental condition $i$ and $j$ are evaluated by paired rank-sum (Wilcoxon) tests of the average outcome value (of wealth or population growth) in all places under condition $i$ versus $j$, at a significance level of $5 \%$.

First, population growth (as our indicator of net migration) is no different in the agricultural shock variant than in the baseline, nor in the specialization variant. Only in the full shock variant is it lower; in fact, population growth in the full shock variant is the lowest of all variants. However, both the agricultural shock and full shock variant differ from the baseline and each other in terms of what layers are occupied. Second, the size of portfolios and the diversity of layers occupied is greater in the specialization variant. We examine the underlying processes for these in detail below.

\subsubsection{Shock Experiments}

To understand the impact of the shocks, we examine the path of layer occupancy over time in the baseline and identify deviations from this path in the shock variants. Generally speaking, agents opted over time to shift into occupation of the extractive industry and social service industry layers in the baseline (Figure 6A); we do not claim that there is particular real-world meaning to this, as this process embeds both the spin-up from a random initial assignment of layers, as well as poor data on the costs of switching industries and joining these layers in our data. Rather, we intend only to present these as a baseline against which to compare our shocks.

In the agricultural shock variant, we see only small changes - following the shock at timestep 50, a movement out of agriculture, with slight redistribution to other layers in the same place; there may also be additional migration out, but we do not observe a significant effect of this (Figure 6B). By contrast, in the full shock variant, we observe movement away from all layers relative to the baseline (Figure 6C) - a clear out-migration effect, in comparison to the substitution effect observed in the agricultural shock variant.

\subsubsection{Specialization Experiment}

The specialization variant includes two additional variations on each of the basic 10 layers of income sources, with i) higher costs to access, ii) higher time commitments (meaning it is not possible to combine multiple income sources in the same livelihood), and iii) higher wage rates. These variations simulate 'specializing,' such as an unskilled worker investing in learning a trade, an employee paying for training and qualifications necessary for promotion, or perhaps a piece-rate producer engaging more in their task and earning more. There is no explicit link in the dataset between the low, mid, and high variants of a particular layer, so that movement across different industries is also possible - perhaps as a service industry employee studying nights to eventually become a teacher, as an example. 


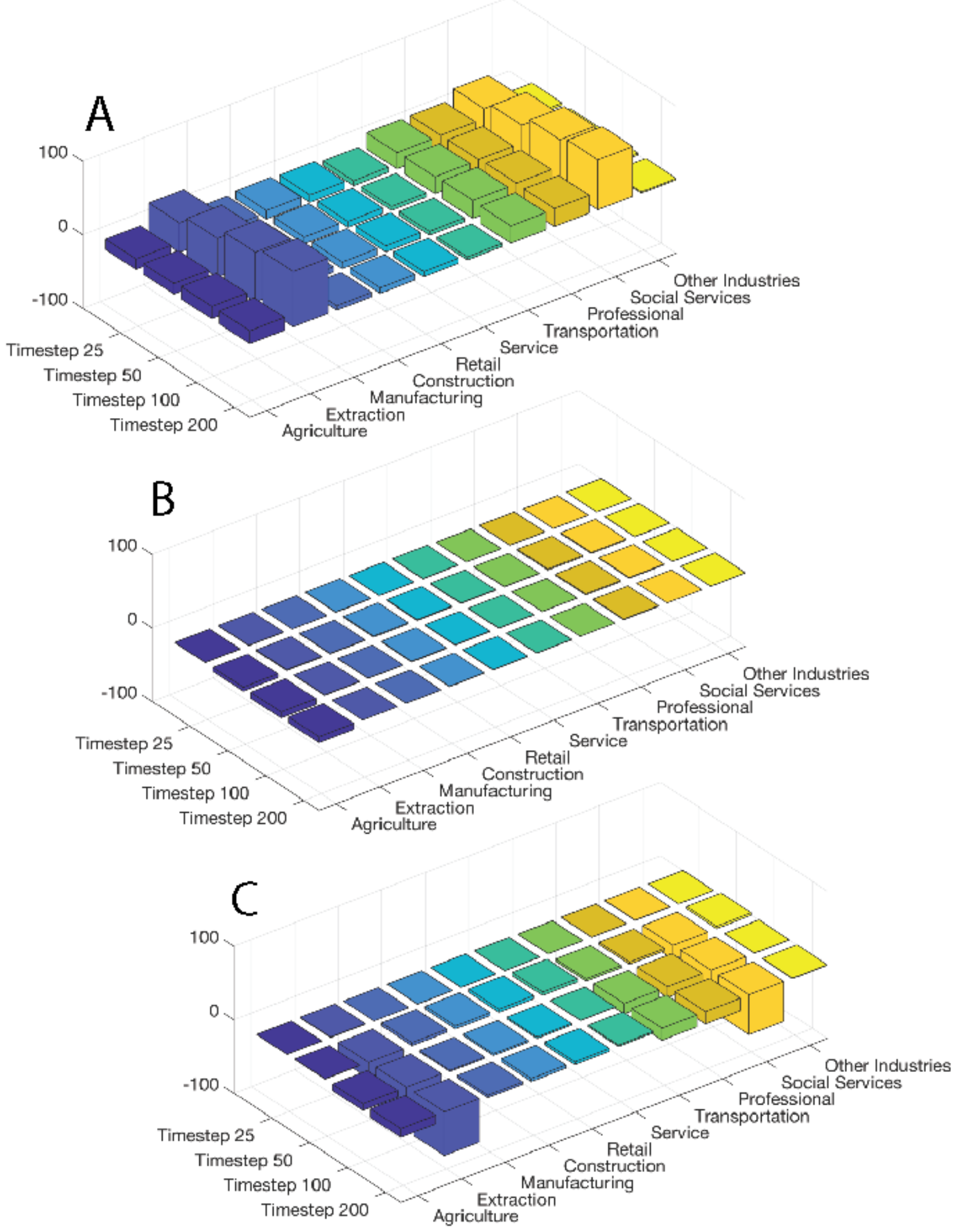

Figure 6: Average number of agents occupying layers across all places at timesteps 25, 50 (time of shock), 100, and 200. A) Baseline experiment. B) Difference of Agricultural Shock Experiment and Baseline. C) Difference of Country Shock and Baseline.

We observe in the specialization variant similar distributions across income categories, but lower occupation of the basic 10 layers as some agents have specialized and now occupy the 'high' variant of these same industries (Figure 7). We do not observe agents occupying the 'mid' variants, suggesting that they were not sufficiently 
distinct from the 'high' layers to lead to any kind of partial specialization; future experiments will explore this more carefully.

Who are these 'high' agents? Compared with their peers in the same places, a model outcome is that the agents who have settled in the places with access to 'high' layers:

- $\quad$ Are more risk-loving (higher $r$ values than those in 'low' layers, by KS test at $5 \%$ )

- Have moved more times before arriving, by KS test at $5 \%$

- Are significantly more likely to have bought a home in this place, by KS test at $5 \%$

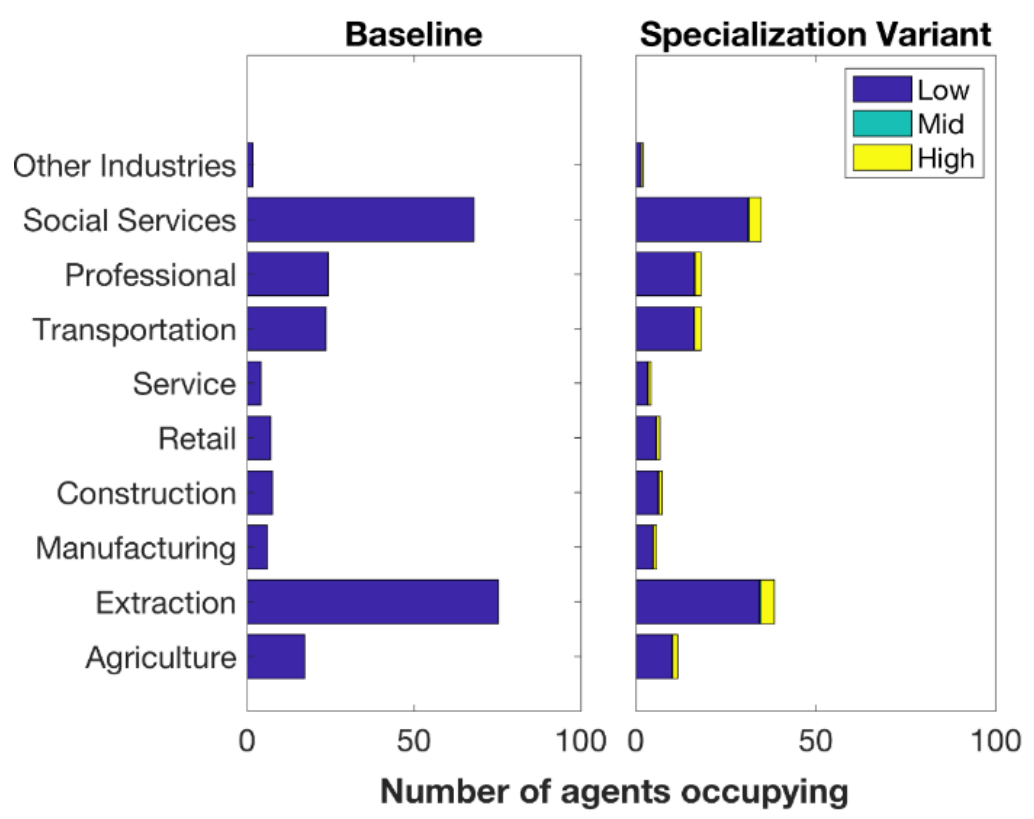

Figure 7: Average number of agents occupying layers across all places at end of simulation (Timestep 200), in Baseline (left) and Specialization variant (right). In the Specialization variant, 'Low' layers represent the basic layers in the Baseline, 'Mid' layers are the first level of specialization and 'High' layers are the second level of specialization.

This last factor is noteworthy as agents in the current set of simulations are not credit constrained - any one agent could choose to purchase a home if they considered it part of their best portfolio. Overall the greater level of exploration and risk taking, and the investment in higher incomes and homes suggests that the data layer infrastructure present in our experiment - including the opportunity for specialization as well as moorings offering use value - are sufficient to allow the emergence of something akin to a 'professional class.' Perhaps more than any of the other results presented here, this finding highlights the unique contribution of MIDAS. Whereas in the Kniveton et al. (2011) model, migration rates and the characteristics of who migrates are determined by the census dataset used to drive the model, the emergence of livelihoods within MIDAS (rather than the strict definition by an input dataset) lets the distribution of who migrates and when this occurs emerge from the model. At the level of the individual agent (as is presented in this study), this could include migration decisions put in abeyance by access to a new professional opportunity or strengthening of a local social network safety net; similarly, it could include migrations enabled by the growth of a diaspora of close connections in another part of the world. With extension of MIDAS to capture households (such as by a group of agents with close social connections, maximizing joint utility and undergoing demographic change), this could grow to include the geographic dispersion of children for new opportunity enabled by the accumulation of wealth and capital. This capacity is critical if we are to model migration under the yet-unexperienced conditions of a changing climate, for which no analog yet exists in a census dataset or otherwise. 


\section{Discussion}

We demonstrated some of the strategic responses to opportunities that are possible in a true PPM modeling framework, including substitution of income streams, the choice to specialize or diversify, as well as to migrate in response to shocks. We observed what may be the emergence of a class of agents (which we dub a 'professional class') within one of our experiments, highlighting the value of tools like MIDAS to capture migration and adaptive behaviors under conditions for which analogs do not yet exist in census datasets or otherwise.

\subsection{Limitations in MIDAS and in this study}

We did not examine all of the capabilities of the MIDAS framework, such as an evolving social network or utility layers that are determined endogenously (such as wage rates that are dependent upon labor supply, for example), nor did we focus on predicting future patterns of migration in the area of interest. Our choice to restrict analysis to a narrow set of stylized experiments, and defer efforts at detailed simulation, calibration, and validation, highlights the limitation that demand for data places on MIDAS. Stepping down from a gravity model to an individual decision model introduces a host of factors potentially shaping decision-making - trade-offs that individuals face across income, costs, and access to family or amenities like schools, health care, nature and leisure - that need to be parameterized. This is a broader challenge that agent-based models beyond MIDAS face, and it is worth noting that it is not resolved by simply excluding these other factors - this in itself is implicitly an assumed parameterization (of 'zero,' typically). Making use of MIDAS and models like it requires deliberate engagement with how each of the many moving parts are parameterized or excluded, whether they are parameterized from data or through calibration, and what one's assumptions about these pieces imply for model findings.

For MIDAS, this will likely mean that building realism into migration and adaptation decisions will need to be stepwise, in order that it is meaningful and effects are properly attributed. Klabunde and Willekens (2016) highlight the importance of household demography in both theory and modeling of migration processes, for example, and a next MIDAS effort might compare validation outcomes of a MIDAS application (such as the current application to US-Mexico) without and with household change (e.g., tight social network ties among a group of agents as a household, and changes in their planning horizon over time as household members age). Other efforts might independently compare different modes of reproducing the 'status quo bias' via mooring factors (Sun et al., 2017) including family, assets, or even changes in the way risk preferences and perspectives are represented. One reviewer of this manuscript suggested the simulation of privilege and access in equity by managing agent ordering, as well as the incorporation of long-term health effects of different livelihoods choices; many possibilities exist for refining the decision set that agents face, and it may be that reaching a decision set that validates well for a particular context requires a series of separate, tractable investigations.

\subsection{Informing MIDAS Behavior}

We directed our efforts in this study at identifying the model parameters with the greatest importance in shaping key outcomes (of wealth, income diversity, and migration) when agents face a simple decision set including wage incomes and a simple mooring factor.

Overall, we find a small set of behavioral parameters - risk preferences, utility coefficients, or discount rates to be critical determinants of model outputs. This has major implications for the work of informing agent-based models from social datasets, as parameters such of this are not typically collected within large-n household surveys; much more typically, they are determined experimentally in lab settings with smaller participant pools (Janssen \& Ostrom, 2006). It is relatively common to parameterize ABM from secondary datasets such as census or integrated household survey efforts, as was the case in Kniveton et al. (2011) cited earlier, and our findings here demonstrate the limitations of this approach for modeling livelihood decisions in which multiple factors (which may matter differently to the agent) are considered simultaneously.

In reality, this problem of non-identified agent preferences is already widely present in the ABM literature; measures of the trade-offs individuals face among pushes, pulls, and moorings are critical missing pieces in modeling efforts at the individual (agent) level. To cite only a few - Agrawal et al. (2013) report having to make 
assumptions about the comparative utility of consumption vs. leisure, Magliocca et al. (2013) miss data on tradeoffs between environmental amenities and housing costs, Tsai et al. (2015) have no empirical data to understand farmers' valuation of ecosystem services, and Hassani-Mahmooei and Parris (2012) are left to model the relative importance of house and land ownership vs. employment opportunities with random numbers. Researchers wishing to predict livelihoods (including migration) are left either to make assumptions, or sidestep the modeled decision entirely. For example, drawing on the large dataset of household-level migration activity in the Mexican Migration Project (MMP), Nawrotzki et al. (2015) identify in their econometric analysis a different set of drivers for households' first migration events than what predict their last (most recent) migration events - and from this draw the inference that social and community factors (in the new location, not measured directly) must intervene to reshape the decision. This is a valuable inference, but direct measurement of preferences and the structure of the decision would be of much greater value for predicting migration as a choice.

Fortunately, mobile and smartphone subscriptions have spread across both the urban and rural world in recent years (ITU, 2016), and Bell (2017) outlines this novel opportunity to bring behavioral data into models in a 'large $\mathrm{n}$-and- $\mathrm{t}^{\prime}$ fashion, capturing high-frequency assessments of individual preferences and actions across broad populations, in at least two distinct ways. The first is to sift through the massive volumes of secondary data already generated by mobile phones through mobile transactions as well as through text and call data. Lu et al. (2016) analyze call detail records (CDR) from mobile phones in Bangladesh to tease out patterns in migration following cyclones, developing thus a method to identify regularity and seasonality in migration patterns and detect responses to shocks. Blumenstock et al. (2016) examine transfers of airtime and call records to detect social network structure following earthquake activity in Rwanda. At a broader scale, these and other researchers have applied CDR, coupled with other remotely-sensed data, to map out basic poverty indices (Blumenstock et al., 2015; Steele et al., 2017). On its own, this large-n secondary data may not provide the experimental conditions for measuring behavior, but it does provide a massive set of revealed preferences (through actions such as calling, moving, or sharing) that may provide a better set of behavioral outcomes against which to match patterns (using behavioral parameters like risk preferences as calibration parameters), as in pattern-oriented modeling approaches (Grimm et al., 2005). However, it is not the only opportunity for data gathering that mobile devices provide.

The second mode is by using smartphones to transform our mode of engagement with rural communities and generate primary data via 'micropayment for microtasks' platforms (Bell et al., 2016). Enenkel et al. (2015) developed a user-friendly front-end for the Android-based survey tool Open Data Kit in order to capture highfrequency snapshots of food security and prices from mobile device holders in Central African Republic; Bell et al. (2016) developed a similar tool to collect diaries of food and water consumption and labor activity in Bangladesh. Using the more-established technology of short message service (SMS), Van der Windt and Humphreys (2016) characterized the dynamics of conflict and the role of aid interventions in the Democratic Republic of Congo. The opportunity to engage a mobile user directly provides an opportunity to collect highfrequency primary data, including experimental tasks, by transforming social data collection from an oftenexpensive, half- or whole-day long survey into a set of regular 'microtasks' of minutes at a time. Perhaps counter-intuitively, Grossman et al. (2014) have found this mode of data collection to be more representative than traditional surveys, conditional on having access to a device, because it frees respondents up to engage in their own time, and does not constrain participation to those who are able to take an afternoon or day away from work. Further, where there is opportunity to link individual responses to the larger universe of CDR, it provides an unprecedented opportunity to validate experimentally derived behavioral parameters (from microtasks) on revealed preferences (from CDR).

Together, these two modes of social data collection via mobile device can provide exactly the kind of large-nand-t behavioral data needed to parameterize a theory-driven model of adaptation such as MIDAS, where in particular there is need to characterize agent preferences given trade-offs across different forms of utility (income, use value, or access, e.g.) and across differences in reliability over time. The experiments we have presented here illustrate several aspects of migration and livelihoods decisions captured within the MIDAS modeling framework where such behavioral data would be of value. Future efforts with MIDAS will target particular sets of data (such as resource sharing over social networks, or utility preferences revealed in stated choice experiments, for example) and identify their role in improving predictions of migration, among other adaptive strategies. 


\section{Conclusions}

We presented a novel framework (MIDAS) that examines migration alongside other adaptive strategies by implementing the push-pull-mooring (PPM) theory of migration. A key feature of MIDAS is that it allows a range of livelihood features - sharing via social networks, income sources, use value of assets and sense of place - to simultaneously shape the construction of a livelihood portfolio; with this increased modeling capacity comes a great reliance on behavioral data. We demonstrated through a small set of experiments varying access to income in particular places how agents might be motivated to shift elements of their livelihood portfolio or to migrate, and how this decision depended strongly on a small number of behavioral parameters, key among them preferences for risk, for different forms of utility, and for time. Future work integrating mobile secondary and primary data will identify the contribution these data can make in improving predictions of migration and adaptation.

\section{References}

Adams, H., \& Adger, W. N. (2013). The contribution of ecosystem services to place utility as a determinant of migration decision-making. Environmental Research Letters, 8(1), 15006. http://doi.org/10.1088/1748-9326/8/1/015006

Adger, W. N., Arnell, N. W., Black, R., Dercon, S., Geddes, A., \& Thomas, D. S. G. (2015). Focus on environmental risks and migration: causes and consequences. Environmental Research Letters, 10(6), 60201. http://doi.org/10.1088/17489326/10/6/060201

Adger, W. N., Dessai, S., Goulden, M., Hulme, M., Lorenzoni, I., Nelson, D. R., Naess, L. O., Wolf, J., \& Wreford, A. (2009). Are there social limits to adaptation to climate change ? Climatic Change, 93, 335-354. http://doi.org/10.1007/s10584008-9520-z

Agrawal, A., Brown, D. G., Rao, G., Riolo, R., Robinson, D. T., \& Bommarito, M. (2013). Interactions between organizations and networks in common-pool resource governance. Environmental Science and Policy, 25, 138-146. http://doi.org/10.1016/j.envsci.2012.08.004

Ajzen, I. (1991). The theory of planned behavior. Organizational Behavior and Human Decision Processes, 50, 179-211. http://doi.org/10.1016/0749-5978(91)90020-T

Anderson, J. E. (2010). The Gravity Model (NBER Working Paper Series No. 16576). Cambridge, MA. Retrieved from: http://www.nber.org/papers/w16576.pdf

Barnett, J., \& Webber, M. (2010). Accommodating Migration to Promote Adaptation to Climate Change (Policy Research Working Paper No. 5270). Washington, DC. Retrieved from http://ipcc-wg2.gov/njlite_download2.php?id=9888

Barrett, C. B., Reardon, T., \& Webb, P. (2001). Nonfarm income diversification and household livelihood strategies in rural Africa: Concepts, dynamics, and policy implications. Food Policy, 26(4), 315-331. http://doi.org/10.1016/S03069192(01)00014-8

Bell, A. (2016). MIDAS (Migration, Intensification, and Diversification as Adaptive Strategies). http://doi.org/10.5281/zenodo.154738

Bell, A. R. (2017). Informing decisions in agent-based models: A mobile update. Environmental Modelling and Software, 93, 310-321. http://doi.org/10.1016/j.envsoft.2017.03.028

Bell, A. R., Robinson, D. T., Malik, A., \& Dewal, S. (2015). Modular ABM development for improved dissemination and training. Environmental Modelling \& Software, 73, 189-200. http://doi.org/10.1016/j.envsoft.2015.07.016

Bell, A., Ward, P., Killilea, M., \& Tamal, M. E. H. (2016). Real-time social data collection in rural Bangladesh via a "microtasks for micropayments" platform on Android smartphones. PLoS ONE, 11(11), e0165924. http://doi.org/10.1371/journal.pone.0165924

Bert, F. E., Podestá, G. P., Rovere, S. L., Menéndez, Á. N., North, M., Tatara, E., Laciana, C. E., Weber, E. \& Toranzo, F. R. (2011). An agent based model to simulate structural and land use changes in agricultural systems of the argentine pampas. Ecological Modelling, 222(19), 3486-3499.

Blumenstock, J., Cadamuro, G., \& On, R. (2015). Predicting poverty and wealth from mobile phone metadata. Science, 350(6264), 1073-1076. http://doi.org/10.1126/science.aac4420

Blumenstock, J., Eagle, N., \& Fafchamps, M. (2016). Airtime transfers and mobile communications: evidence in the aftermath of natural disasters. Journal of Development Economics, 120, 157-181. http://doi.org/10.1016/j.jdeveco.2016.01.003

Bogue, D. J. (1969). Principles of demography. Wiley. Retrieved from https://books.google.com/books?id=QRszAAAAMAAJ

Bollig, M. (2016). Adaptive cycles in the savannah: pastoral specialization and diversification in northern Kenya. Journal of Eastern African Studies, 10(1), 21-44. http://doi.org/10.1080/17531055.2016.1141568

Borjas, J. (1987). Self-Selection and the Earnings of Immigrants. American Economic Review, 77(4), 531-553.

Cannon, T. (2013). Rural livelihood diversification and adaptation to climate change Terry. In J. Ensor, R. Berger, \& S. Huq (Eds.), Community Based Adaptation to Climate Change: emerging lessons (pp. 55-75). Practical Action Publishing. 
Dave, C., Eckel, C., Johnson, C., \& Rojas, C. (2010). Eliciting Risk Preferences: When is Simple Better ? Journal of Risk and Uncertainty, 41(3), 219-243.

Enenkel, M., See, L., Karner, M., Álvarez, M., Rogenhofer, E., Baraldès-Vallverdú, C., Lanusse, C., \& Salse, N. (2015). Food security monitoring via mobile data collection and remote sensing: Results from the Central African Republic. PLoS ONE, 10(11), e0142030. http://doi.org/10.1371/journal.pone.0142030

Espindola, A., Silveira, J., \& Penna, T. (2006). A Harris-Todaro Agent-Based Model to Rural-Urban Migration. Brazilian Journal of Physics, 36(3A), 603-609. http://dx.doi.org/10.1590/S0103-97332006000500002.

Feder, G. (1980). Farm Size, Risk Aversion and the Adoption of New Technology under Uncertainty. Oxford Economics Papers, 32(2), 263-283.

Filho, H. S. B. (2011). Migration and Social Networks - An Explanatory Multi-evolutionary Agent-Based Model.

Grimm, V., Revilla, E., Berger, U., Jeltsch, F., Mooij, W. M., Railsback, S. F., Thulke, H.-H., Weiner, J., Wiegand, T., \& DeAngelis, D. L. (2005). Pattern-Oriented Modeling of Agent-Based Complex Systems: Lessons from Ecology. Science, 310(5750), 987-991. http://doi.org/10.1126/science.1116681

Grossman, G., Humphreys, M., \& Sacramone-Lutz, G. (2014). "I wld like u WMP to extend electricity 2 our village": On Information Technology and Interest Articulation. American Political Science Review, 108(3), 688-705. http://doi.org/10.1017/S0003055414000331

Hare, M., \& Deadman, P. (2004). Further Towards a Taxonomy of Agent-Based Simulation Models in Environmental Management. Mathematics and Computers in Simulation, 64, 25-40. https://doi.org/10.1016/S03784754(03)00118-6

Hassani-Mahmooei, B., \& Parris, B. W. (2012). Climate change and internal migration patterns in Bangladesh: An agent-based model. Environment and Development Economics, 17, 763-780. http://doi.org/10.1017/S1355770X12000290

Hong, G. 2015. Examining the role of amenities in migration decisions: A structural estimation approach. Papers in Regional Science, 95(4).

Hussein, K., \& Nelson, J. (1998). Sustainable Livelihoods and Livelihood Diversification. IDS Working Paper (Vol. 69). Retrieved from http://opc-prd.ubib.eur.nl:8080/DB=3/LNG=EN/PPN?PPN=236411659/

INEGI (2017). Encuesta Nacional de Ocupación y Empleo (ENOE), población de 15 años y más de edad. Retrieved from http://www.beta.inegi.org.mx/proyectos/enchogares/regulares/enoe/

ITU (2016). Key ICT indicators for developed and developing countries and the world (totals and penetration rates). Retrieved from https://www.itu.int/en/ITU-D/Statistics/Documents/statistics/2016/ITU_Key_2005-2016_ICT_data.xls

Janssen, M. A., \& Ostrom, E. (2006). Empirically Based, Agent-based models. Ecology and Society, 11(2), 37.

Kahneman, D. (2003). Maps of Bounded Rationality: Psychology for Behavioral Economics. The American Economic Review, 93(5), 1449-1475.

Kennan, J., \& Walker, J. (2011). The effect of expected income on individual migration decisions. Econometrica, 79(1), 211251. http://doi.org/10.3982/ECTA4657

Klabunde, A., \& Willekens, F. (2016). Decision-Making in Agent-Based Models of Migration : State of the Art and Challenges. European Journal of Population, 32(1), 73-97. http://doi.org/10.1007/s10680-015-9362-0

Kniveton, D. R., Smith, C. D., \& Black, R. (2012). Emerging migration flows in a changing climate in dryland Africa. Nature Climate Change, 2(6), 444-447. http://doi.org/10.1038/nclimate1447

Kniveton, D., Smith, C., \& Wood, S. (2011). Agent-based model simulations of future changes in migration flows for Burkina Faso. Global Environmental Change, 21, S34-S40. http://doi.org/10.1016/j.gloenvcha.2011.09.006

Kuipers, E. (2014). The differentiated impact of agricultural transformations on livelihood strategies.

Lu, X., Wrathall, D. J., Sundsøy, P. R., Nadiruzzaman, M., Wetter, E., Iqbal, A., Qureshi, T., Tatem, A., Canright, G., Eng $\varnothing-$ Monsen, K., \& Bengtsson, L. (2016). Unveiling hidden migration and mobility patterns in climate stressed regions: A longitudinal study of six million anonymous mobile phone users in Bangladesh. Global Environmental Change, 38, 17. http://doi.org/10.1016/j.gloenvcha.2016.02.002

Magliocca, N. R., Brown, D. G., \& Ellis, E. C. (2013). Exploring agricultural livelihood transitions with an agent-based virtual laboratory: global forces to local decision-making. PloS One, 8(9), e73241. http://doi.org/10.1371/journal.pone.0073241

Mastrorillo, M., Licker, R., Bohra-Mishra, P., Fagiolo, G., D. Estes, L., \& Oppenheimer, M. (2016). The influence of climate variability on internal migration flows in South Africa. Global Environmental Change, 39(July), 155-169. http://doi.org/10.1016/j.gloenvcha.2016.04.014

Moon, B. (1995). Paradigms in migration research: exploring "moorings" as a schema. Progress in Human Geography, 19(4), 504-524. http://doi.org/10.1177/030913259501900404

Mueller, V., Gray, C., \& Kosec, K. (2014). Heat Stress Increases Long-term Human Migration in Rural Pakistan. Nature Climate Change, 4(3), 182-185. http://doi.org/10.1038/nclimate2103

Müller, B., Bohn, F., Dreßler, G., Groeneveld, J., Klassert, C., Martin, R., Schlüter, M., Schulze, J., Weise, H., Schwarz, N. (2013). Describing human decisions in agent-based models - ODD+D, an extension of the ODD protocol. Environmental Modelling and Software, 48, 37-48. http://doi.org/10.1016/j.envsoft.2013.06.003

Munshi, K. (2003). Networks in the Modern Economy : Mexican Migrants in the U.S. Labor Market. The Quarterly Journal of Economics, 118(2), 549-599.

Munshi, K., \& Rosenzweig, M. (2016). Networks and Misallocation : Insurance, Migration, and the Rural-Urban Wage Gap. American Economic Review, 106(1), 46-98. 
Naivinit, W., Le Page, C., Trébuil, G., \& Gajaseni, N. (2010). Participatory agent-based modeling and simulation of rice production and labor migrations in Northeast Thailand. Environmental Modelling and Software, 25(11), 1345-1358. http://doi.org/10.1016/j.envsoft.2010.01.012

Nawrotzki, R. J., Riosmena, F., Hunter, L. M., \& Runfola, D. M. (2015). Amplification or suppression: Social networks and the climate change-migration association in rural Mexico. Global Environmental Change, 35, 463-474. http://doi.org/10.1016/j.gloenvcha.2015.09.002

Ravenstein, E. (1885). The Laws of Migration. Journal of the Statistical Society of London, 48(2), 167-235.

Roy, A. (1951). Some Thoughts on the Distribution of Earnings. Oxford Economics Papers, 3(2), 135-146.

Rubinstein, A. (1998). Modeling Bounded Rationality. MIT University Press, Cambridge, MA.

Scheffran, J., Marmer, E., \& Sow, P. (2012). Migration as a contribution to resilience and innovation in climate adaptation: Social networks and co-development in Northwest Africa. Applied Geography, 33(1), 119-127. http://doi.org/10.1016/j.apgeog.2011.10.002

Schlüter, M., Baeza, A., Dressler, G., Frank, K., Groeneveld, J., Jager, W., Janssen, M. A., Mcallister, R. R. J., Müller, B., Orach, K., Schwarz, N. \& Wijermans, N. (2017). A framework for mapping and comparing behavioural theories in models of social-ecological systems. Ecological Economics, 131, 21-35.

Smith, C. D. (2014). Modelling migration futures: development and testing of the Rainfalls Agent-Based Migration Model Tanzania. Climate and Development, 6(1), 77-91. http://doi.org/10.1080/17565529.2013.872593

Sociedad Hipotecaria Federal (2018). SHF - Sociedad Hipotecaria Federal, S.N.C. Institucion de Banca de Desarrollo. Retrieved August 14, 2018, from https://www.shf.gob.mx/avaluos/extranet

Steele, J. E., Sundsøy, P. R., Pezzulo, C., Alegana, V. A., Bird, T. J., Blumenstock, J., Bjelland, J., Eng ø-Monsen, K., de Montjoye, Y.-A., Iqbal, A.M., Hadiuzzaman, K.N., Lu, X., Wetter, E., Tatem, A.J., \& Bengtsson, L. (2017). Mapping poverty using mobile phone and satellite data. Journal of The Royal Society Interface, 14(127), 20160690. http://doi.org/10.1098/rsif.2016.0690

Stimson, R. J., \& McCrea, R. (2004). A push-pull framework for modelling the relocation of retirees to a retirement village: The Australian experience. Environment and Planning A, 36(8), 1451-1470.

Sun, Y., Liu, D., Chen, S., Wu, X., \& Shen, X. (2017). Understanding users' switching behavior of mobile instant messaging applications: An empirical study from the perspective of push-pull- mooring framework. Computers in Human Behavior, 75, 727-738. http://doi.org/10.1016/j.chb.2017.06.014

Tacoli, C. (2009). Crisis or adaptation? Migration and climate change in a context of high mobility. Environment and Urbanization, 21(2), 513-525. http://doi.org/10.1177/0956247809342182

Trulia (2018) All United States Real Estate Guides by State. Retrieved August 14, 2018, from https://www.trulia.com/home_prices/

Tsai, Y., Zia, A., Koliba, C., Bucini, G., Guilbert, J., \& Beckage, B. (2015). An interactive land use transition agent-based model (ILUTABM): Endogenizing human-environment interactions in the Western Missisquoi Watershed. Land Use Policy, 49, 161-176. http://doi.org/10.1016/j.landusepol.2015.07.008

US Bureau of Labor Statistics (2017). Quarterly Census of Employment and Wages. Retrieved from https://www.bls.gov/cew/

U.S. Embassy \& Consulates in Mexico (2018). Visas I U.S. Embassy \& Consulates in Mexico. Retrieved August 14, 2018, from https://mx.usembassy.gov/visas/.

Van der Windt, P., \& Humphreys, M. (2016). Crowdseeding in Eastern Congo : Using Cell Phones to Collect Conflict Events Data in Real Time. Journal of Conflict Resolution, 60(4), 748-781. http://doi.org/10.1177/0022002714553104

World Bank (2017). Remittance Prices Worldwide: Making markets more Transparent. Retrieved December 20, 2017, from https://remittanceprices.worldbank.org/en

Zillow, Inc. (2018). United States Home Prices \& Home Values | Zillow. Retrieved August 14, 2018, from https://www.zillow.com:443/home-values/ 